\title{
STATISTICAL FAILURE MODEL OF BONES
}

\author{
M. PITHIOUX* ${ }^{*}$ P. CHABRAND ${ }^{\dagger}$ and F. MAZEROLLE ${ }^{\ddagger}$ \\ Laboratoire de Mécanique et d'Acoustique, CNRS, \\ 31 Ch. Joseph Aiguier 13402 Marseille Cedex 20, France \\ *pithioux@lma.cnrs-mrs.fr

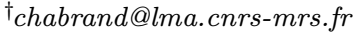 \\ ${ }^{\ddagger}$ mazerolle@lma.cnrs-mrs.fr
}

\begin{abstract}
In clinical research, knowledge of the mechanical behavior of bones is helpful for diagnostics and therapeutic processes and the failure of compact bones is a necessary study in clinical analysis, accidentology, and traumatology. The purpose of this paper is to analyse the failure properties of compact bones using a statistical model to interpret stress and strain measurements obtained by INSTRON and X-ray scanner devices. Samples were prepared from a lamellar structure of compact bovine bones and the density of each sample is controlled and taken to be constant $\left(1.9 \mathrm{~g} / \mathrm{cm}^{3}\right)$. The experimental results data thus depend only on defects in the samples. This model may help physicians and surgeons predict bone failure when inserting a prosthesis, for example.
\end{abstract}

Keywords: Compact bone; X-ray scanner; traction experiments; statistical model; constitutive laws.

\section{Introduction}

Bone failure often occurs in accidental shock but is also sometimes the result of bone diseases (osteoporosis, cancer), and can occur during prosthesis insertion in a clinical context. Cortical bones exhibit tear, damage and failure mechanisms when they receive shocks. Failure of compact bones is representative of brittle behavior when bones are subjected to tensile stresses. It is then observed that failure strain and stress vary greatly from one experiment to another, so that the failure stress is mainly the result of the defects distribution; the largest defect in the structure will create failure. Brittle failure is presently analyzed by a statistical model which is validated by experimental studies performed using a traction device. Damage and failure of compact bones have already been studied in tensile experiments (Burstein, A. H. et al. 1972, Carter, D. R., Hayes, W. C. 1977, Cooke, F. W. et al. 1973, Norman, T. L. et al., 1996, Pope, M. H., Outwater, J. O., 1972, Reilly, D.T., Burstein, A. H. 1975, Sedlin, E. D. 1965). Results obtained by these authors show large variations in the values of the failure stress (from 100-200 MPa) and failure strain (from $0.4-4 \%$ ), so there is little precision in the mechanical characteristics of compact bones. None of these authors have developed a statistical model to analyze 
this large variation in the mechanical properties of compact bones at failure. The purpose of this paper is to develop a statistical model to help explain the results obtained by experiments performed on bones with a density which vary slightly around $1.9 \times 10^{3} \mathrm{~kg} / \mathrm{m}^{3}$, subjected to tensile loading. This statistical law is used to analyze the failure stress variation, and may help in developing a constitutive law of compact bones.

\section{Material and Methods}

Among the parameters which can influence the failure of compact bones, we will highlight only bone density and microscopic structure. To reduce these parameters, a procedure is developed using an X-ray scanner and a microscope which can analyze the sample density and structure. We use an X-ray scanner ND8000 of the Laboratoire de Mécanique et d'Acoustique (Desrues, J. et al. 1996, Bonnenfant, D. et al. 1998). With this scanner, images are created on different sections of bone. The sections are taken at every $10 \mathrm{~mm}$ on a $110-\mathrm{mm}$ long sample (Fig. 1).

We then analyze more precisely the density variation in the section, and this varies slightly through the lamellar structure of every bones studied (around $1.9 \times$ $\left.10^{3} \mathrm{~kg} / \mathrm{m}^{3}\right)$. In the osteonal structure, the density varies between $1.8 \times 10^{3} \mathrm{~kg} / \mathrm{m}^{3}$ and $2.1 \times 10^{3} \mathrm{~kg} / \mathrm{m}^{3}$. The scanner image obtained in one section of a bone is presented in Fig. 2.

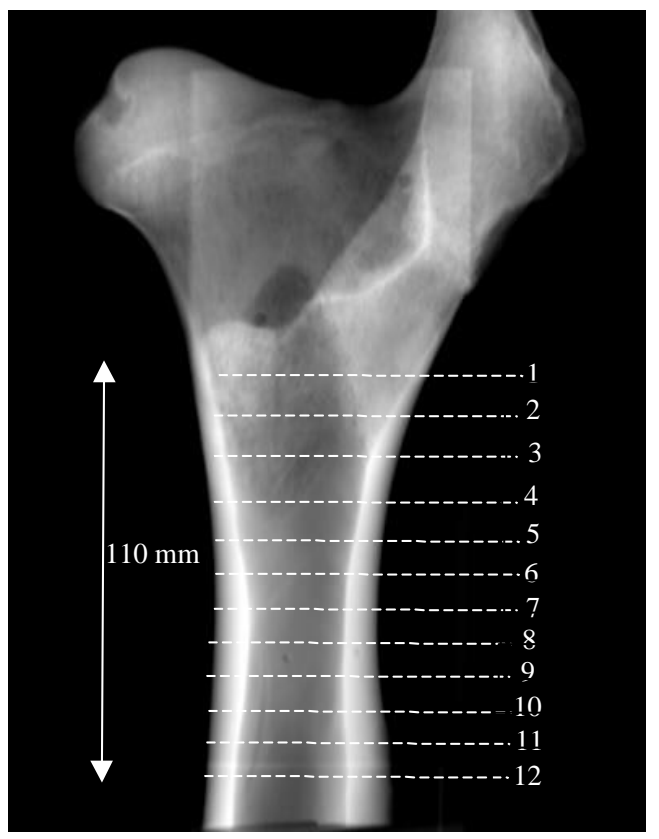

Fig. 1. Radiological image of a bovine bone. 


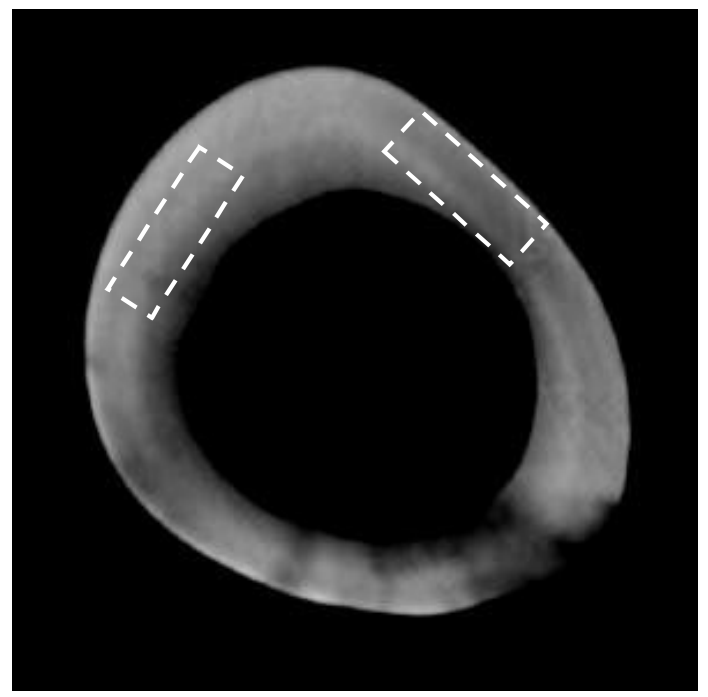

Fig. 2. Scanner image of a transverse section (samples were cut from the areas in rectangles).

The samples were taken from ten fresh bovine femoral bones. Two samples were cut in areas where the density varied slightly (around $1.9 \times 10^{3} \mathrm{~kg} / \mathrm{m}^{3}$ ) in the anterior lateral and anterior medial. These samples have a lamellar structure. Tensile experiments were developed using an INSTRON machine (Fig. 3) used at various velocities $(0.5-50 \mathrm{~mm} / \mathrm{min})$ with a $500-\mathrm{kg}$ tensile force.

The epiphyses were cut so as to be able to focus only on compact bone. Testpieces were obtained by first cutting bones in the axial direction and then removing the marrow from each part. Samples were then machined with a numerical device, and shaped as shown in Fig. 4(a). In the center, the sample width is reduced in order

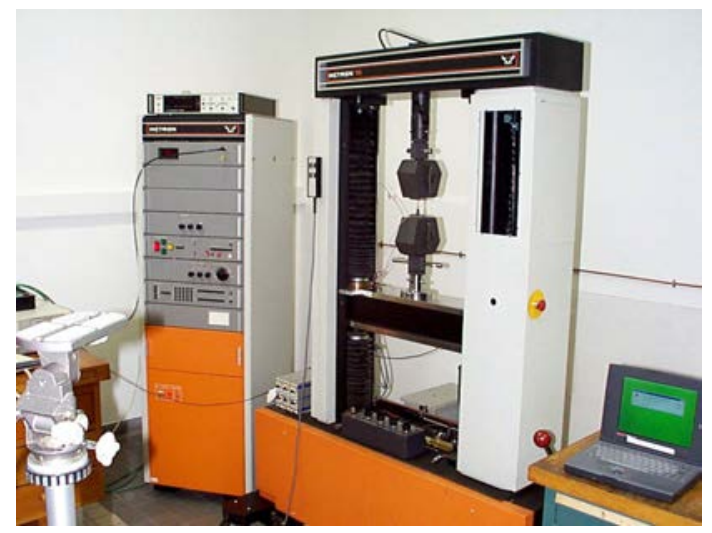

Fig. 3. INSTRON device. 


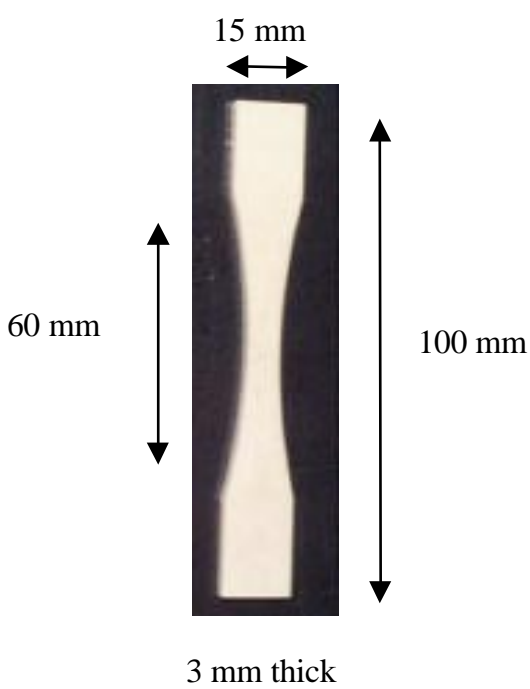

(a)

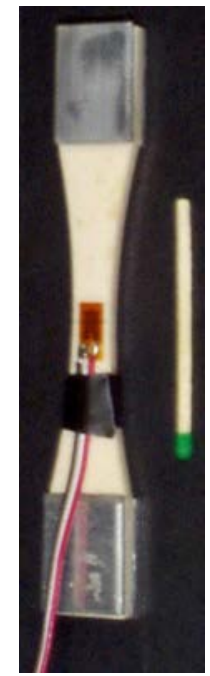

(b)

Fig. 4. (a) Sample geometry (b) sample equipped with a strain gauge.

to make sure that failure will be localized in this part of the sample and not close to the ends. Lastly, a strain gauge was applied to measure the local deformation of the sample during the failure process (Fig. 4(b)). A statistical model was developed to analyze the tensile results.

\section{Statistical Model}

As density has a large influence on the failure process, and as we studied samples with low density variation, we can assume that the results depend mainly on the presence of a defect which will be taken into account. The statistical model developed to estimate the failure behavior of compact bones analyzes brittle failure of bones.

We consider a structure of volume $V$, consisting of $N$ elementary volumes $V_{0}^{i}$.

$V_{0}^{i}$ must be small enough to contain a few fissures and large enough to be independent of neighboring volumes.

Let $p_{R_{i}}\left(\sigma, V_{0}^{i}\right)$ (respectively $\left(P_{R}(\sigma, V)\right)$ be the failure probability of the volume element $V_{0}^{i}$ (resp. volume $V$ ) subjected to stress $\sigma$. The quantity $1-p_{R_{i}}\left(\sigma, V_{0}^{i}\right)$ (resp. $1-P_{R}(\sigma, V)$ ) is the probability of non-failure of the volume $V_{0}^{i}$ (resp. $V$ ) subjected to one-dimensional tensile stress $\sigma$ :

$$
1-P_{R}(\sigma, V)=\prod_{i=1}^{N}\left(1-p_{R_{i}}\left(\sigma, V_{0}^{i}\right)\right)
$$


The logarithm of Eq. (1) can be expressed:

$$
\ln \left[1-P_{R}(\sigma, V)\right]=\sum_{i=1}^{N} \ln \left[1-p_{R_{i}}\left(\sigma, V_{0}^{i}\right)\right]
$$

Considering the material homogenous, every elementary volume has the same failure probability. As the volume $V$ is divided into $N$ elementary volumes $V_{0}$, where $N=\frac{V}{V_{0}}$, we get:

$$
\ln \left[1-P_{R}(\sigma, V)\right]=N \ln \left[1-p_{R}\left(\sigma, V_{0}\right)\right]
$$

The failure probability $f(\sigma)$ is given by:

$$
P_{R}(\sigma, V)=1-\exp \left(-\frac{V}{V_{0}} f(\sigma)\right)
$$

The stress function is defined as:

$$
f(\sigma)=\ln \left[\frac{1}{1-p_{R}\left(\sigma, V_{0}\right)}\right]
$$

To approximate this unknown function, Weibull proposed the function $f(\sigma)$ (Beremin, F. M. 1983, Weibull, W. 1939 and 1951, Hild, F., Domergue, J. M. 1994, Hild, F., Feillard, P. 1997) such that:

$$
f(\sigma)=\left(\frac{\sigma-\sigma_{u}}{\sigma_{0}}\right)^{m}
$$

In this expression, $\sigma_{u}$ is the stress threshold under which the failure probability is zero. We assume that the stress threshold is usually equal to zero $\left(\sigma_{u}=0\right)$.

With $f(\sigma)=\left(\frac{\sigma}{\sigma_{0}}\right)^{m}$, Eq. (4) can be written as:

$$
\ln \left[\ln \left(\frac{1}{1-P_{R}(\sigma, V)}\right)\right]=\operatorname{mln} \sigma+K
$$

with

$$
\left.K=\operatorname{mln}\left(\frac{V}{V_{0}}\right)^{\frac{1}{m}} \sigma_{0}\right)
$$

When we graph $\ln \left[\ln \left(\frac{1}{1-P_{R}(\sigma, V)}\right)\right]$ as a function of $\ln \sigma$, points are aligned on a straight line. The slope of this straight line is equal to Weibull's modulus $\mathrm{m}$. In the Weibull law, parameters $V_{0}$ and $\sigma_{0}$ are not independent. $V_{0}$ is the failure stress of a structure containing a volume $V_{0}$. Local stress-strain curves were generated by experiments with the traction machine to determine failure stress and failure strain variation (Fig. 5). The statistical model is then used to calculate the probability of obtaining failure. 


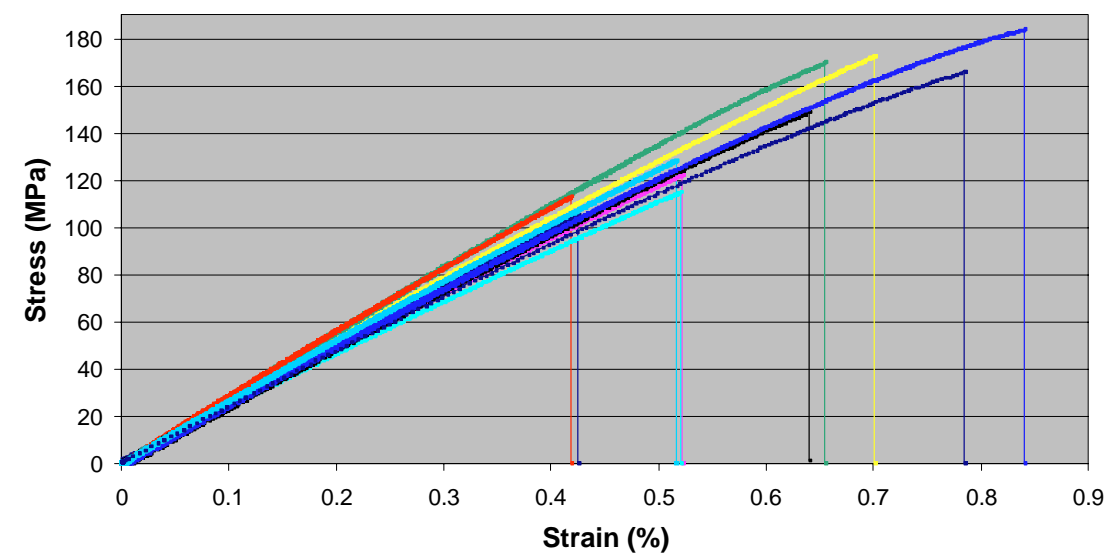

Fig. 5. Stress-strain curves obtained with the INSTRON device for ten samples. Experiments were performed at a strain rate of $0.5 \mathrm{~mm} / \mathrm{min}$

\section{Results}

\subsection{Experiments Measured Using the INSTRON Device}

From these results, the local mechanical properties of compact bones were deduced where failure occurred. Stress-strain curves can be divided into two parts (Fig. 5). The first part of the curve is a linear elastic region in which the Young's modulus of the bones can be calculated. The curves then becomes weakly nonlinear. This part can be assimilated to a damaged region. Finally, failure occurs suddenly.

Failure stress can vary by about 53\%, and the Young's modulus about $35 \%$, which is quite a broad domain of variation (Table 1). However, these results are in line with those published in the literature (Burstein, A. H. et al. 1972, Reilly, D. T., Burstein, A. H. 1975, Currey, J. D. 1970, Cezayirlioglu, H. et al. 1985).

\subsection{Statistical Model}

The Weibull statistical model described in the method is used to analyze the experimental data. The experimental failure probability $P_{R}$ is deduced from Table 1. Then we plot $\ln \left[\ln \left(\frac{1}{1-P_{R}\left(\sigma_{\mathrm{ult}}, V\right)}\right)\right]$ as a function of $\ln \sigma_{\mathrm{ult}}$ (Fig. 6). Finally, the curve

Table 1. Variation of the failure stress $\left(\sigma_{u} l t\right)$ and the failure strain $\left(\varepsilon_{u} l t\right)$ obtained with the INSTRON device.

\begin{tabular}{lc}
\hline & Results \\
\hline$E(\mathrm{MPa})$ & $17000 \leq E \leq 26000$ \\
$\sigma_{u l t}(M P a)$ & $100 \leq \sigma_{u l t} \leq 190$ \\
$\varepsilon_{u l t}(\%)$ & $0.4 \leq \varepsilon_{u l t} \leq 1$ \\
\hline
\end{tabular}


Failure probability

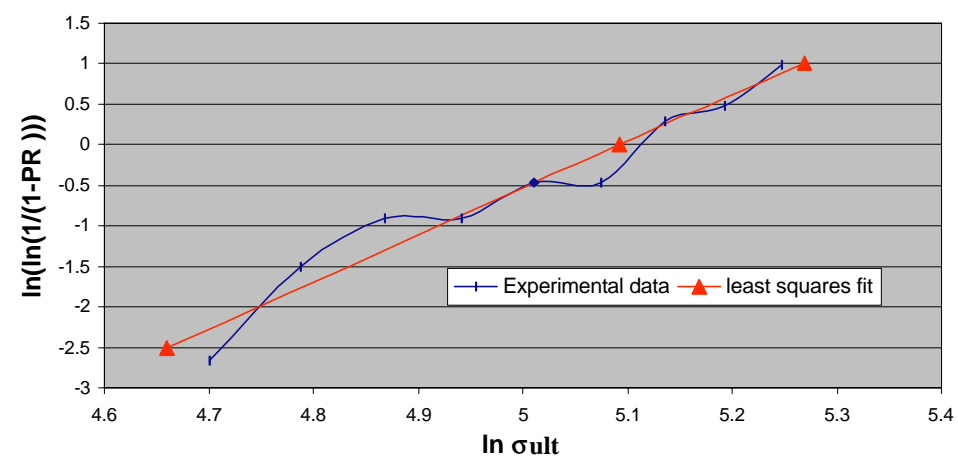

Fig. 6. Analyze of experimental measurements and least squares fit on a logarithmic scale.

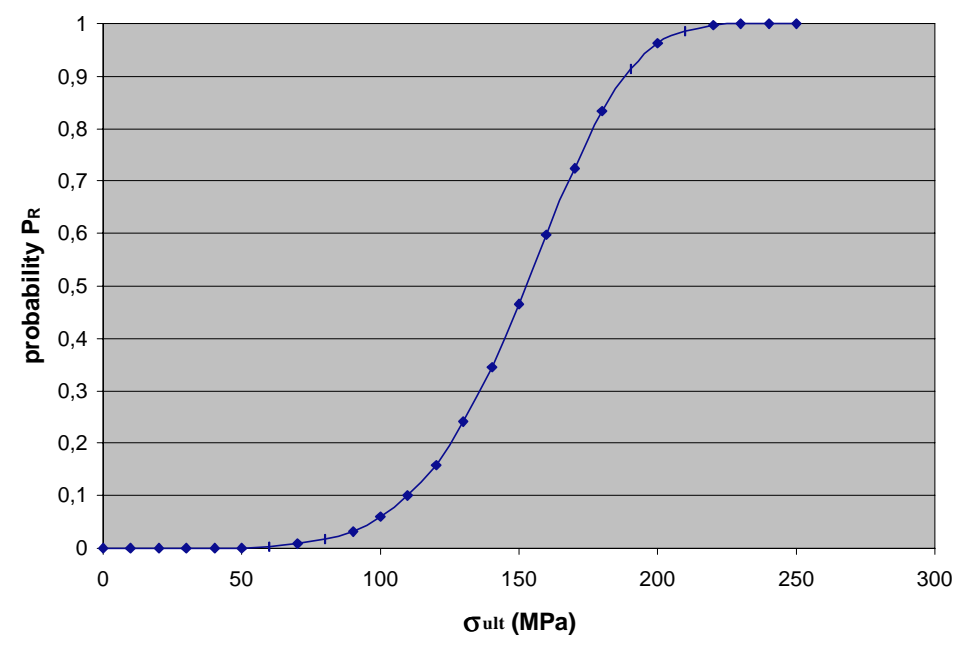

Fig. 7. Failure probability law of compact bones.

(Fig. 6) obtained is approximated by a straight line using a least squares fit (Fig. 6):

$$
\ln \left[\ln \left(\frac{1}{1-P_{R}\left(\sigma_{\mathrm{ult}}, V\right)}\right)\right]=5.75 \ln \sigma_{\mathrm{ult}}-29.3
$$

Considering the volume $V$ chosen as the volume of the structure $\left(1980 \mathrm{~mm}^{3}\right), \sigma_{0}$ is equal to $43.5 \mathrm{MPa}$.

The failure probability law is then defined by:

$$
P_{R}\left(\sigma_{\mathrm{ult}}\right)=1-e^{-\left[\frac{\sigma_{\mathrm{ult}}}{162.7}\right]^{5.75}}
$$

This law plotted in Fig. 7 is the failure probability and corresponds to a constitutive law of compact bones. 
Using this law, we can say that there is no possibility of sample failure before $50 \mathrm{MPa}$; a $46 \%$ chance of failure before $150 \mathrm{MPa}$; and certainty of sample failure after a stress greater than $220 \mathrm{MPa}$.

\section{Discussion and Conclusion}

A statistical model was developed to analyze bone failure, and thus to improve physicians' knowledge of this phenomenon in clinical applications. We first performed tensile tests to analyze the variation of failure stress and failure strain. The brittle behavior of compact bones shows that the failure strain varies between 100 $\mathrm{MPa}$ and $190 \mathrm{MPa}$, which corresponds to a range of $53 \%$. An important point of this work is that the samples tested were always taken from the same part: anterior lateral and anterior medial part of the bone with a controlled density. Then the structure of the samples was analyzed and samples were cut only on the lamellar structure of the bovine femur. This is a new approach for studying bone characteristics, combining the use of a microscope, an X-ray scanner and an INSTRON device. The use of a strain gauge makes it possible to obtain local results: the strain is measured where the failure appears in the sample. Compact bone properties are comparable to a brittle material, so the results can be analyzed by a statistical model. The statistical method also provides a prediction of bone failure, which is important for surgeons when inserting a prosthesis, for example. In parallel of these experimental studies, we perform a numerical model of the microscopic behavior of compact bone at failure. Our topic is to link the statistical model at the macroscopic level with the microscopic model (Pithioux, M. 2000).

\section{References}

[1] Beremin, F. M., A local criterion for cleavage fracture of a nuclear pressure vessel steel, J. Metallurg. Trans., 14A (1983), 2277-2287.

[2] Bonnenfant, D., Mazerolle, F., Suquet, P., Compaction of powders containing hard inclusions: Experiments and micromechanical modeling, Mech. Materials, 29 (1998), 93-109.

[3] Burstein, A. H., Currey, J. D., Frankel, V. H., Reilly, D. T., The ultimate properties of bone tissue: The effects of yielding, J. Biomech., 5 (1972), 35-44.

[4] Carter, D. R., Hayes, W. C., Compact bone fatigue damage, Clin. Orthop. Rel. Res., 127 (1977), 265-274.

[5] Cezayirlioglu, H., Bahniuk, E., Davy, D. T., Heiple, K. G., Anisotropic yield behavior of bone under combined axial force and torque, J. Biomech., 18(n1) (1985), 61-69.

[6] Cooke, F. W., Zeidman, H., Scheifele, S. J., The fracture mechanics of bone - Another look at composite modeling, J. Biomed. Materials Res. Symp., (4) (1973), 383-399.

[7] Currey, J.D., The mechanical properties of bone, Clin. Orthop. Rel. Res., 73 (1970), 210-231.

[8] Desrues, J., Chambon, R., Mokni, M., Mazerolle, F., Void ratio evolution inside shear bands in triaxial sand specimens studied by computed tomography, Géotechnique, 46 (1996), 529-546. 
[9] Hild, F., Domergue, J. M., Tensile and flexural ultimate strength of fiber-reinforced ceramic-matrix composites, Int. J. Solids Structures, 31(7) (1994), 1035-1045.

[10] Hild, F., Feillard, P., Ultimate properties of fiber-reinforced composites, Reliability Engineering and System Safety, 56 (1997), 225-235.

[11] Norman, T. L., Nivargikar, S. V., Burr, D. B., Resistance to crack growth in human cortical bone is greater in shear than in tension, J. Biomech., 29 (1996), 1023-1031.

[12] Pithioux, M., Lois de comportement et modéles de rupture des os longs, University Aix Marseille II, thesis (2000).

[13] Pope, M. H., Outwater, J. O., The fracture characteristics of bone substance, J. Biomech., 5 (1972), 457-465.

[14] Reilly, D. T., Burstein, A. H., The mechanical properties of cortical bone, J. Bone Joint Surg., 56, 1001-1022.

[15] Sedlin, E.D., A rheologic model for cortical bone, Acta Orthopedica Scandinavica, Suppl. 83 (1965).

[16] Weibull, W., A statistical theory of the strength of materials, Ing. Vetenskap Akad. Handl., 12 (1939), 5-45.

[17] Weibull, W., A statistical distribution function of wide applicability, J. Appl. Mech., 18 (1951), 293-297. 